\title{
Mechanical Causation of Biological Structure: Productive Pulls Produce Persistent Filaments in a Human Fibroblast Model of Matrix Development
}

Alexandra A. Silverman ${ }^{1}$, Seyed Mohammad Siadat, Ph.D. ${ }^{1}$, Jason D. Olszewski ${ }^{1}$ and Jeffrey W. Ruberti, Ph.D. ${ }^{1}$

${ }^{1}$ Department of Bioengineering, Northeastern University, Boston, MA

\section{Summary}

During development, mesenchymal cells direct the elaboration of extracellular matrix that shapes the initial animal Bauplan which subsequently grows to produce mechanically-competent structure. To gain insight into the processes that initiate matrix formation at the cellular level, high temporal and spatial resolution videos were obtained from a primary human corneal fibroblast (PHCF) cell culture system known to produce an organized, collagenous stroma similar to a human cornea. The videos were taken over a 4-day period as the culture was approaching confluency, which permitted a clear view of cell kinematics and any elaborated filaments. The movies reveal an active cellular system in which the PHCFs execute five types of high-velocity and high extensional strain-rate "pulls" that produce persistent filaments. In four of the pull types, average maximum strain rates $\left(\sim 0.1-0.33 \mathrm{~s}^{-1}\right)$ were adequate to induce aggregation and/or crystallization in crowded biopolymer systems. The results demonstrate that PHCFs have the capacity to mechanically induce the formation of biopolymer structures intercellularly and in the path of force.

\section{Keywords}

Morphogenesis, Mechanobiology, Extracellular Matrix Filaments, Primary Human Corneal Fibroblasts, Extensional Strain, Biopolymers, Flow-Induced Crystallization, Tunneling Nanotubes, Gondola-Like Vesicles, Macromolecular Crowding 


\section{Introduction}

The function of load-bearing and other highly-specialized tissues (e.g. the cornea) is critically dependent on the precise placement and preferential retention of structural material directly in the path of mechanical force. How fibroblastic cells, working together with their associated molecular secretome, efficiently generate a fully-continuous, mechanically-competent structural matrix, orders of magnitude larger than themselves, remains poorly understood ${ }^{1}$. The precise mechanisms driving matrix formation remain obscure principally because it is difficult to observe morphogenesis at high enough temporal and spatial resolution to determine the fate of structural molecules as they move from synthesis, to secretion, to incorporation into the forming extracellular matrix (ECM). Thus, most knowledge has been gained indirectly through destructive, high spatial resolution electron microscopy ${ }^{2-7}$ or lower spatial resolution optical microscopy ${ }^{6,7}$. Regarding temporal resolution, the information available is much sparser with very few live studies focused on ECM deposition ${ }^{8,9}$. We are thus left with little data capable of explaining structural causality with respect to organized connective tissue formation. We do know that collagen, the most abundant structural protein in vertebrates, spontaneously assembles into disorganized fibrillar gels in vitro, and undergoes highly-controlled assembly in vivo to create collagen fibrils, which are the fundamental structural elements in vertebrates. We postulate that local kinematic motions on a micrometer length scale, employed by fibroblastic cells that are actively producing and organizing collagen fibrils, are critical drivers of ECM morphogenesis.

Quite early on in experimental matrix biology, kinematics and mechanics were identified as potentially critical mechanisms determining tissue form ${ }^{10,11}$. It was shown that filaments can appear even without immediate contact with cells ${ }^{12,13}$ and that exerting tension with needles, movements of cells ${ }^{14}$, or any action that causes shrinkage of the intercellular substance ${ }^{15,16}$ could hasten the formation of filaments. It was recognized that "the mere act of pulling one slide over the other leads to the appearance of fibers, which grow in length and bulk ... traverse cell bodies situated in their path ... but the lines of the precipitation are evidently along the lines of strain" 14 .

It was also shown that during matrix formation, connective tissue cells undergo a rapid morphological transformation and "shoot out" long blunt processes ${ }^{17-19}$. Since filaments were found near isolated cell bodies and parallel to these processes, it was suggested that collagen fibril formation is influenced by the orientation of fibroblast cells and the forces acting on a liquid precursor of collagen in the extracellular space ${ }^{18-21}$. Since this early work, we have learned that the formation of collagen fibrils depends on the formation of adhesion complexes on the cell surface ${ }^{22}$, on actin filament formation ${ }^{23}$, on the presence of fibronectin $(\mathrm{FN})^{24}$, and on the ability of cells to provide a force or to "pull"25-27.

We previously hypothesized ${ }^{28}$ that tensile mechanical forces are causative of ECM structure formation by inducing fibrillogenesis of collagen in the path of loads in a manner similar to that found for $\mathrm{FN}^{29}$. In 2016, we demonstrated that extensional strains can directly drive initial collagen fibrillogenesis in vitro ${ }^{28}$ from a solution of collagen molecules. Slowly drawing a microneedle from the surface of a slightly concentrated $\left(\sim 15 \mathrm{mg} / \mathrm{ml}^{30}\right)$ collagen solution created extensional strain rates on the order of $0.3 \mathrm{~s}^{-1}$ and triggered fibril formation in a cell-free system ${ }^{28}$. Extensional strain rate-driven assembly of polymers is referred to as flow-induced crystallization (FIC) ${ }^{31,32}$. 
Extensional strain rates of sufficient magnitude (i.e., large enough to balance the relaxation time of the molecular system being strained; Weissenberg number $>1.0$ ) can result in the alignment of precursor polymer molecules and/or molecular assemblies, potentially lowering the activation energy barrier to polymerization by as much as six orders of magnitude ${ }^{33}$. Self-reinforcement of hydrogels has been reported using strain-induced structural transformation and aggregation of polyethylene glycol chains ${ }^{34}$. Flow-induced aggregation (FIA) of a number of important biomolecules has also been demonstrated ${ }^{35}$, including for tau protein ${ }^{36}$ which forms pathogenic fibers associated with traumatic brain injury. Based on our observations of collagen assembly induced by extensional strains, we suggested that fibroblasts might be capable of initiating tissue formation by pulling receptor-laden "filopodia" through an extracellular macromolecular milieu containing crowded ECM components, including collagen, FN, and hyaluronan (HA). The physics suggested to us that, under the correct conditions, cells had the potential to produce short $(\sim 10$ micron) collagen fibrils between retracting filopodia and in the direction of micro-pulls (see Paten et al. (2016) ${ }^{28}$ : Figure S8). We further postulated that global extensional strains applied to bulk tissues (e.g., via muscle contractions) could complete the tissue rudiment by preferentially fusing collagen fibril ends via FIC, thereby "closing" the gaps between early fibrillar structures (see Paten et al. (2016) ${ }^{28}$ : Figure S8). These two mechanisms (local micro-pulls and global contractions) together suggest a new path to the establishment of ECM organization and its progression to a continuous, mechanically competent structure based on crowded biopolymer aggregation under applied extensional strain. This possible mechanism of ECM structure formation is supported by data which showed that fibroblasts initially deposit short collagen fibril segments in developing tendon that rapidly increase in length by tip fusion at the onset of muscle contraction ${ }^{3,4}$. Further, it has been shown that abrogating muscle contractions during morphogenesis prevents mechanically competent tendon formation and development ${ }^{37-40}$. However, the physicochemical conditions for FIC to occur in our system of pure collagen required collagen concentrations of $\sim 15$ $\mathrm{mg} / \mathrm{ml}$ and extensional strain rates of $\sim 0.3 \mathrm{~s}^{-128}$ which may not be physiological.

We have since extended that work to include FN in the collagen solution and found that FN catalyzes collagen fibril formation via FIC at much lower collagen concentration $(0.5 \mathrm{mg} / \mathrm{ml}$ vs $\sim 15.0 \mathrm{mg} / \mathrm{ml})^{41}$. This recent data places FIC as a potentially important mechanism in the formation of ECM, squarely within the scope of physiological conditions. However, there has been no clear demonstration that fibroblast cells are capable of generating the necessary extensional strain rates to consistently induce FIC, nor has there been any clear demonstration that cells actually "produce" structures via rapid pulling.

An excellent place to examine ECM elaboration is during tissue morphogenesis. The morphogenesis of organized tissue patterns is the result of gene-directed protein expression working in close collaboration with a well-controlled chemical and physical environment. Within this framework, resident fibroblast cells and their specific mechanochemical activities produce the initial tissue anlage that subsequently develops into mature, mechanically-competent structures ${ }^{42}$. Our laboratory has developed an in vitro model of corneal stromal development ${ }^{9,43,44}$ that enables direct observation of morphogenesis of human ECM comprising highly-organized collagen arrays. The model permits live, direct observation of cell-matrix interactions using differential interference contrast (DIC) microscopy at relatively high spatial (structures down to $\sim 30 \mathrm{~nm}$ are 
detectable) and temporal (seconds between images) resolution. Further, the system can be imaged serially over weeks without degradation in the culture ${ }^{9}$. Here, using this in vitro model, we show that primary human corneal fibroblast (PHCF) cells are capable of generating extensional strain rates sufficient to induce collagen FIC, as suggested by our previous reports ${ }^{28,41}$. We also show that the pulling action of our PHCF cells results directly in the formation of persistent filaments.

\section{Results}

\section{Pericellular protrusions and filaments form via multiple types of cell contractions.}

We cultured PHCFs on thin glass to permit 600x DIC observation and seeded the cells below confluence $\left(10,000\right.$ cells $\left./ \mathrm{cm}^{2}\right)$ to observe their initial transition to confluency, which took up to 4 days post-seeding. During this period, we imaged over 100 pulling events in our 48, 1-hour long videos. Live-cell imaging at high temporal (every $5 \mathrm{~s}$ ) and spatial (600x magnification DIC with a detectability limit of $\sim 30 \mathrm{~nm}$ ) resolution captured the motion of PHCFs during the period from initial seeding to attainment of full confluence in vitro. We observed the production of filaments and pericellular protrusions via rapid cellular contractions which we term "pulls". The pulls were productive in that they "caused" the formation of persistent filaments. We identified five types of pulls based on the general morphology of the structure that was providing the contractile motion: 1) flat cell process (CP) pull; 2) thick CP pull; 3) thin CP pull; 4) ultrafine CP pull; and 5) cell surface pull. While we have performed this initial categorization, it is likely that further examination of mechanically-induced filament formation will identify more pull types or further subdivide the ones we have identified. Figure 1 and Supplemental Video 1 show representative pulls of each category along with plots of the measured velocities and extensional strain rates for that particular contraction. Pulls could be performed by a single cell acting alone or by two cells in contact with one another. In cases where two cells were involved, the pulls were further categorized as either symmetric (both cells contracted in what appeared to be a coordinated event) or asymmetric (only one cell contracted). Supplemental Video 2 shows representative movies for the subcategories of symmetric, asymmetric, or single-celled pulling. 

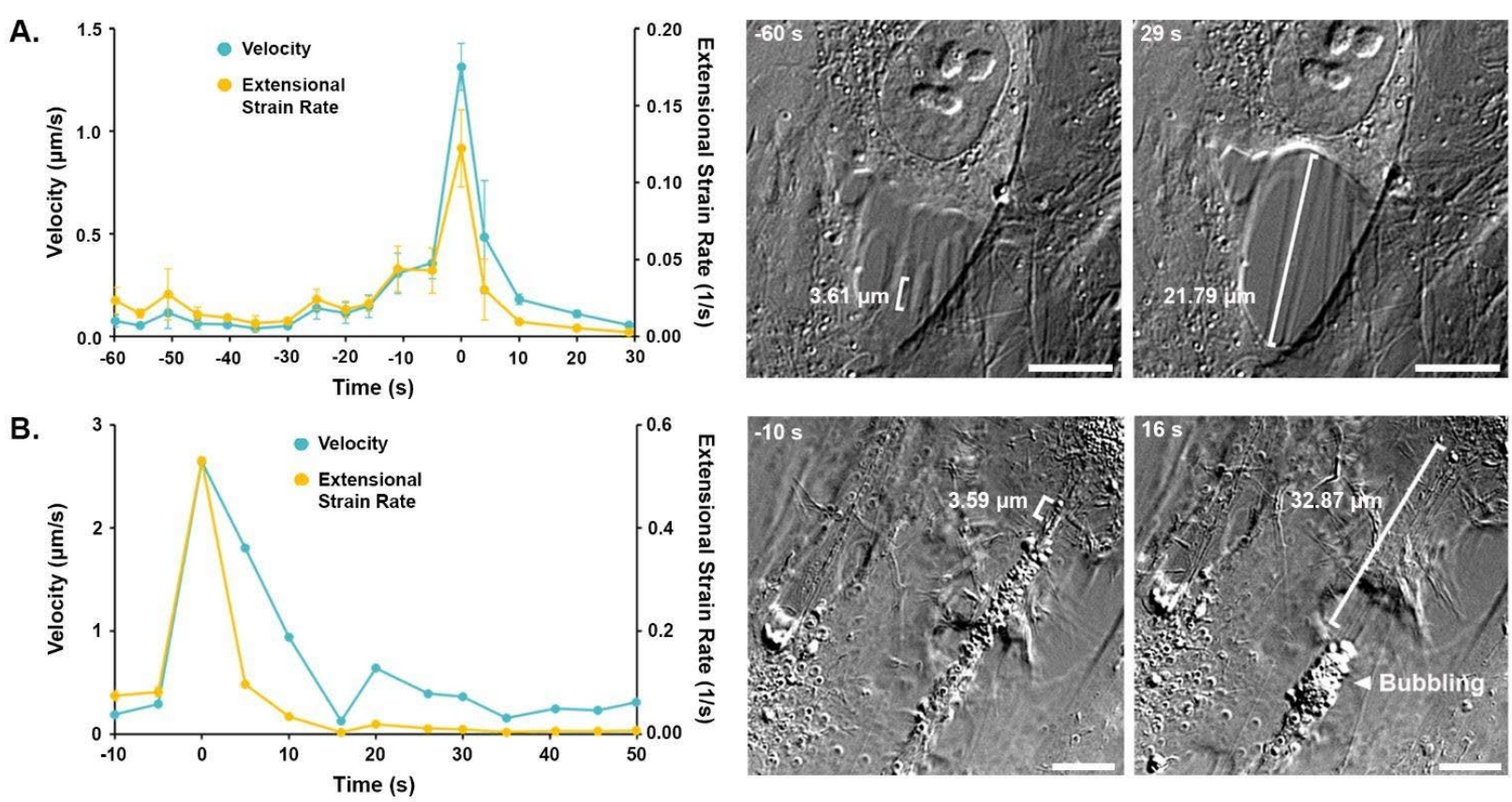

C.
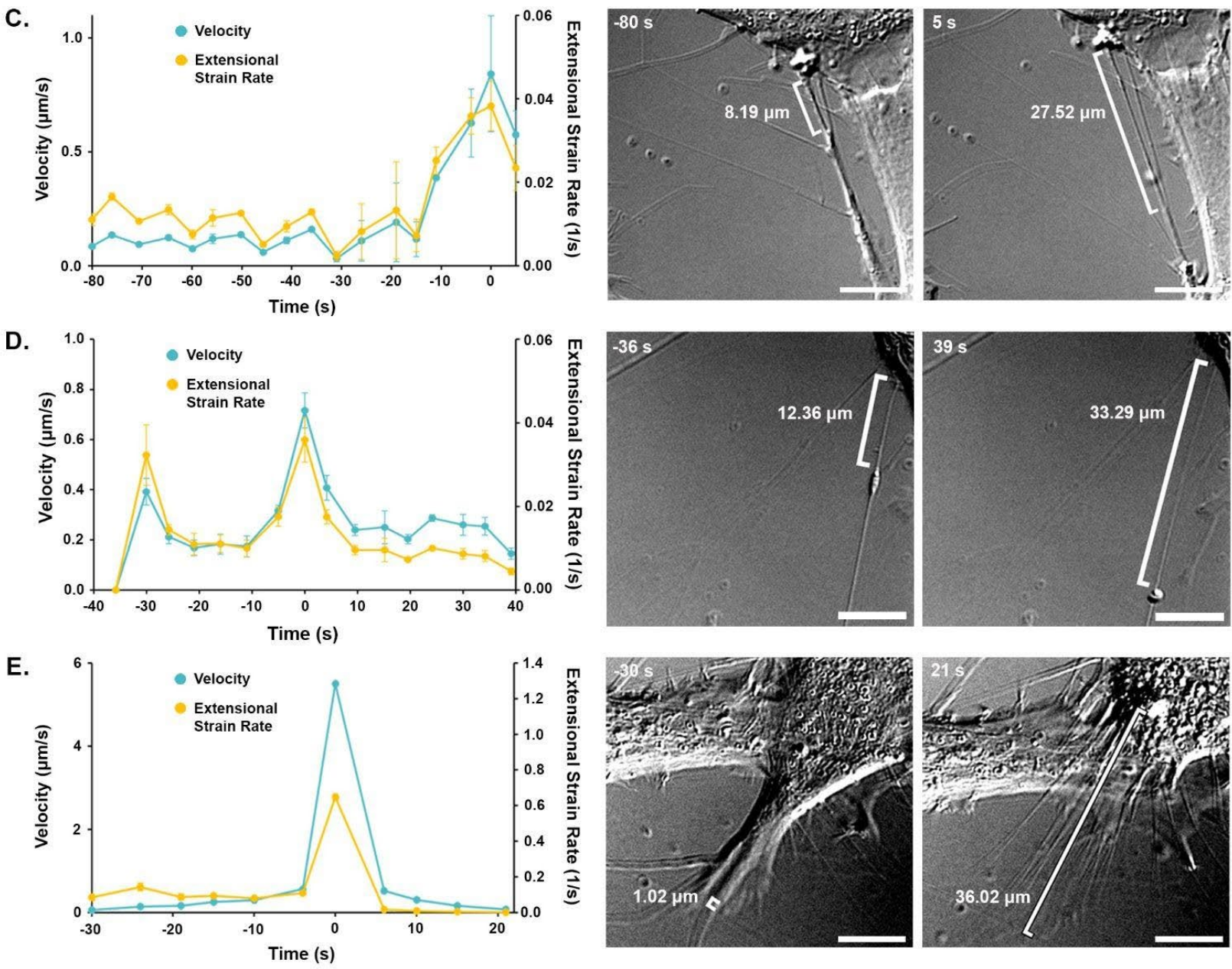
Figure 1. Contraction classifications. A flat CP pull (A), a thick CP pull (B), a thin CP pull (C), an ultrafine CP pull (D), and a cell surface pull (E) are shown along with plots of the measured velocities and extensional strain rates for these specific contractions. The velocities and extensional strain rates were measured by tracking the length of filaments through the duration of the pulling event. The data are shown as mean \pm standard deviation $(n=3$ observers). Scale bars are $10 \mu \mathrm{m}$.

Quantification of the filament formation. For each pulling event that was clearly productive (i.e., produced a filament or filaments), we attempted to track the number of filaments formed and the length of the filaments (e.g., the contraction distance).

Flat CP pulls (Supplemental Video 3) were created by transparent lamellipodia-like projections on the edge of cells. Often, these pulls occurred between the surfaces of two cells, and as the cells separated, the projection was stretched. When a single cell pulled against glass, the transparent projection was adhered to the glass at one end and pulled inward and stretched by the cell. This pulling and stretching mechanism created many nearly parallel filaments aligned along the axis of the pull and perpendicular to the cell border. Each flat CP contraction created $4.8 \pm 2.9(\mathrm{n}=49)$ filaments that were $20.6 \pm 11.3 \mu \mathrm{m}(\mathrm{n}=237)$ long.

Thick CP pulls (Supplemental Video 3) were created by CPs that were $2.8 \pm 0.7 \mu \mathrm{m}(\mathrm{n}=18)$ thick and $41.9 \pm 20.0 \mu \mathrm{m}(\mathrm{n}=18)$ long and often exhibited a wide "foot pad" at their end. Each thick CP pulled in a "starburst" configuration, creating $5.2 \pm 3.0(\mathrm{n}=18)$ filaments that were 21.8 $\pm 11.2 \mu \mathrm{m}(\mathrm{n}=94)$ long and oriented radially around the foot pad. $88.9 \%$ of CPs appeared to be "bubbling," or releasing vesicles into the extracellular space, at their foot pads. Thick CPs were unique in that they were generally in alignment with the cell long axis and often represented the entire trailing edge of a cell.

Thin CP pulls (Supplemental Video 3) were created by $1.3 \pm 0.6 \mu \mathrm{m}(\mathrm{n}=21)$ thick and $15.3 \pm$ $7.2 \mu \mathrm{m}(\mathrm{n}=21)$ long CPs. These CPs frequently exhibited a branched structure at the filamentforming end, and each thin CP pull created $3.8 \pm 1.6(\mathrm{n}=21)$ filaments that were $17.0 \pm 10.0 \mu \mathrm{m}$ $(n=80)$ long. $47.6 \%$ exhibited bubbling, either by the CP itself or by the collaborating cell at the base of the forming filament, which were typically less vigorous and smaller than those exhibited by thick CPs. These pulls were different from thick CP pulls in that they were significantly thinner $(\mathrm{p}<0.05)$, they could be at any angle to the cell long axis, and they did not generally constitute the entire trailing edge of a cell.

Ultrafine CPs (Supplemental Video 3) were reminiscent of tunneling nanotubes and were longer $(48.2 \pm 14.8 \mu \mathrm{m}, \mathrm{n}=5)$ and thinner $(0.9 \pm 0.2 \mu \mathrm{m}, \mathrm{n}=5)$ than other CPs. They always extended between 2 cells, and 4 of the 5 analyzed contained gondola-like vesicles that were transported with the pull.

Finally, some filaments formed directly by inward contraction of the cell surface (Supplemental Video 3). These pulls often occurred when the cell rapidly contracted its trailing edge as it migrated across the field of view, or when two adjacent, parallel cells rapidly separated. In these instances, the inward contraction formed $7.2 \pm 4.7(\mathrm{n}=35)$ filaments that were $27.1 \pm 23.0 \mu \mathrm{m}(\mathrm{n}=211)$ long. These filaments appeared to originate directly from nucleation points on the cell surface, as 
opposed to flat CP filaments which were formed by stretching the flat projection, and cell surface pulls displayed little elaboration of the flat cell border.

Table 1. Summary of number of pulls, filaments formed, filament length, cell process thickness, and cell process length for each pull type.

\begin{tabular}{|l|l|l|l|l|l|l|}
\hline Pull Type & $\begin{array}{l}\text { Number of } \\
\text { Pulls } \\
\text { Identified }\end{array}$ & $\begin{array}{l}\text { Number of } \\
\text { Filaments } \\
\text { formed per } \\
\text { Pull }\end{array}$ & $\begin{array}{l}\text { Total } \\
\text { number of } \\
\text { Filaments } \\
\text { Analyzed }\end{array}$ & $\begin{array}{l}\text { Average } \\
\text { filament } \\
\text { maximum } \\
\text { length }(\mu \mathrm{m})\end{array}$ & $\begin{array}{l}\text { Cell Process } \\
\text { Average } \\
\text { Thickness } \\
(\mu \mathrm{m})\end{array}$ & $\begin{array}{l}\text { Cell Process } \\
\text { Average } \\
\text { Length }(\mu \mathrm{m})\end{array}$ \\
\hline $\begin{array}{l}\text { Flat Cell } \\
\text { Process }\end{array}$ & 50 & $4.8 \pm 2.9$ & 234 & $20.6 \pm 11.3$ & N/A & N/A \\
\hline $\begin{array}{l}\text { Thick Cell } \\
\text { Process }\end{array}$ & 18 & $5.2 \pm 3.0$ & 94 & $21.8 \pm 11.2$ & $2.8 \pm 0.7$ & $41.9 \pm 20.0$ \\
\hline $\begin{array}{l}\text { Thin Cell } \\
\text { Process }\end{array}$ & 21 & $3.8 \pm 1.6$ & 80 & $17.0 \pm 10.0$ & $1.3 \pm 0.6$ & $15.2 \pm 7$ \\
\hline $\begin{array}{l}\text { Ultrafine } \\
\text { Cell } \\
\text { Process }\end{array}$ & 5 & $1.2 \pm 0.4$ & 6 & $60.0 \pm 21.7$ & $1.0 \pm 0.2$ & $48.2 \pm 14.8$ \\
\hline $\begin{array}{l}\text { Cell } \\
\text { Surface }\end{array}$ & 36 & $7.2 \pm 4.7$ & 253 & $26.4 \pm 21.7$ & N/A & N/A \\
\hline
\end{tabular}

\section{Quantification of the pulling kinematics}

Fibril formation kinematics data collected included the velocity and extensional strain rate profiles of each pull. From this data, we report the average maximum values. Generally, the pulls exhibited an initial slow contraction, then a sharp rise to maximum velocity, followed by a sharp decrease as the event ended (see Figure 1 representative plots). Our goal was to quantify the kinematics of the cell motions that were causative of filament formation. While confluency made quantification difficult, contractions could be observed even at day 4 when nearly the entire glass surface was covered by cells and their secreted materials. Supplemental Video 4 shows the progress of the culture from day 1 to day 4 and the increasing cell density. Figure 2 summarizes the number of detected pulls we could reliably quantify on each day; however, this number is not inclusive of all pulls that occurred during the observation period.

The average maximum velocity of the cellular contractions was $(0.80 \pm 0.92 \mu \mathrm{m} / \mathrm{s}, \mathrm{n}=130)$ while the fastest contraction was over $5 \mu \mathrm{m} / \mathrm{s}$, or $\sim 300$ times the average speed of these cells on glass ${ }^{9}$. The PHCFs produced an average maximum extensional strain rate of $0.23 \pm 0.43 \mathrm{~s}^{-1}(\mathrm{n}=130)$ with the highest rate greater than $2.5 \mathrm{~s}^{-1}$. Figure 2 and Table 2 summarize the average maximum pull velocities and extensional strain rates of each contraction type. We note that the maximum extensional strain rates for the flat, thick, and thin CPs were in the range capable of forming collagen fibrils from pure collagen solutions via FIC, as shown by Paten et al. $(2016)^{28}$. However, 
all the pulls quantified, even the slower ones, were "productive" in that they produced filaments (Supplemental Video 5).

A.

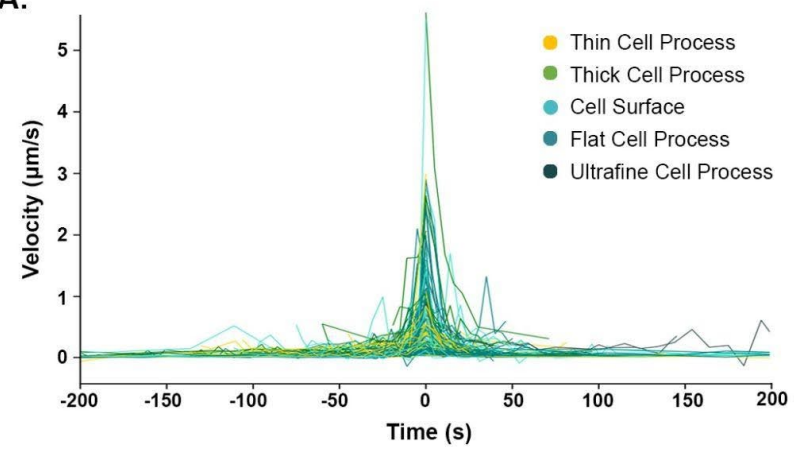

C.

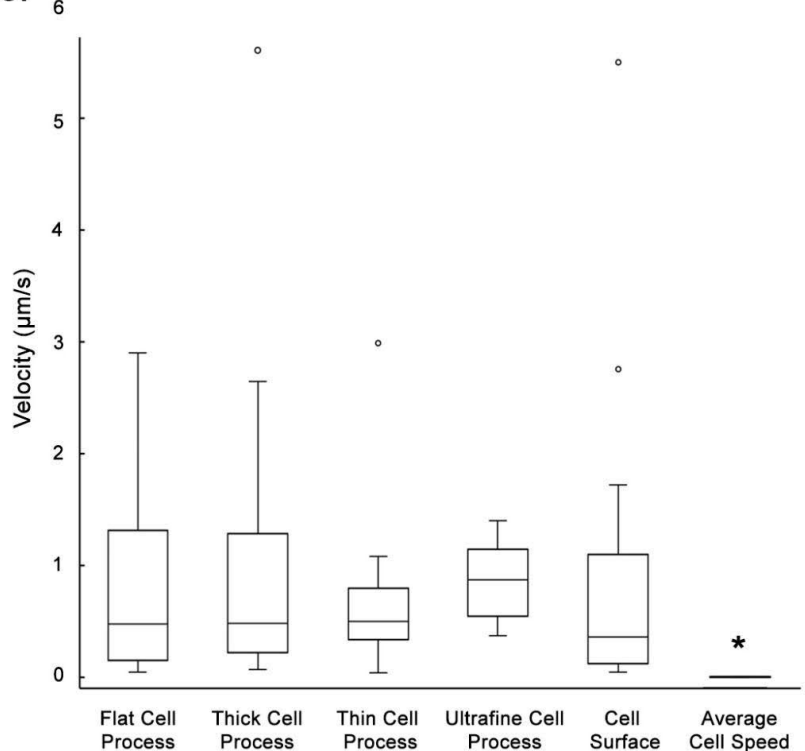

B.

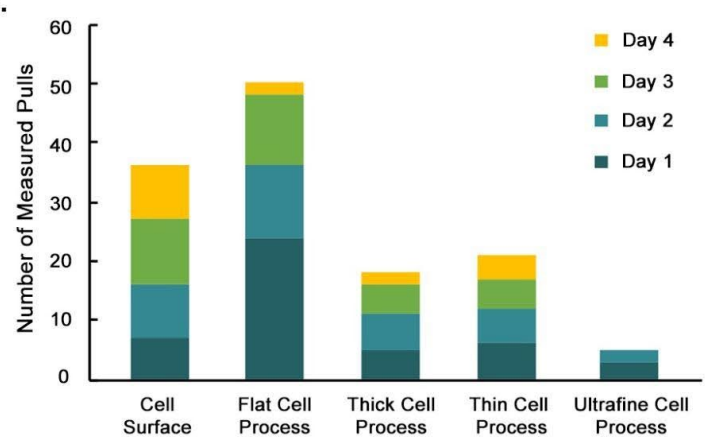

D.

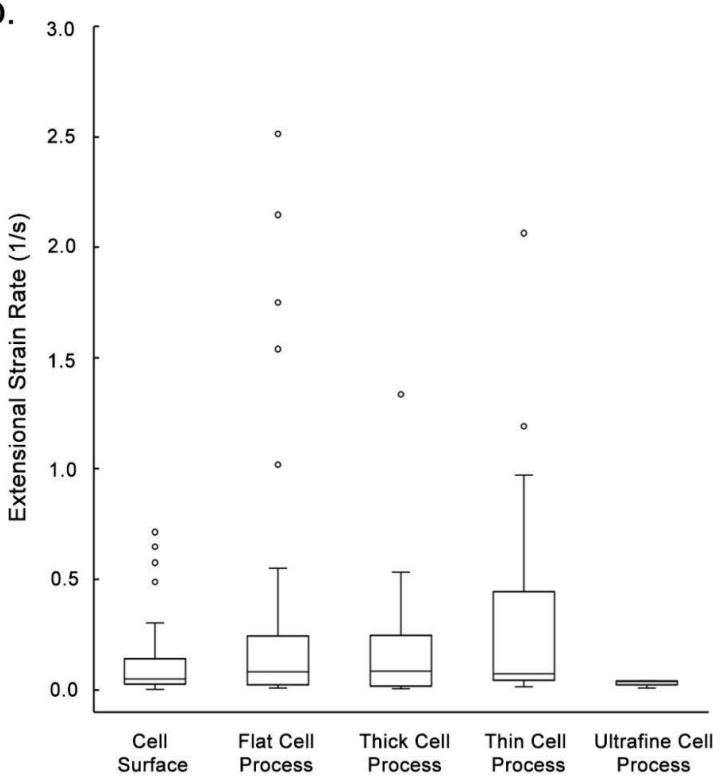

Figure 2. Pull Kinematics. Velocity profiles of assessed contractions (A), and number of contractions assessed (B). Velocity profiles are standardized so the maximum velocity is at time $=0$. Maximum pull velocities $(C)$ and maximum extensional strain rates (D) for each pull type. Asterisk in (C) shows statistical significance $(p<0.01)$.

Table 2. Summary of average maximum pull velocities and extensional strain rates per pull type.

\begin{tabular}{|l|l|l|l|l|l|}
\cline { 2 - 6 } \multicolumn{1}{c|}{} & Cell Surface & $\begin{array}{l}\text { Flat } \\
\text { Cell Process }\end{array}$ & $\begin{array}{l}\text { Thick } \\
\text { Cell Process }\end{array}$ & $\begin{array}{l}\text { Thin } \\
\text { Cell Process }\end{array}$ & $\begin{array}{l}\text { Ultrafine } \\
\text { Cell Process }\end{array}$ \\
\hline Total Contractions & 36 & 50 & 18 & 21 & 5 \\
\hline $\begin{array}{l}\text { Average Maximum } \\
\text { Velocity }(\mu \mathrm{m} / \mathrm{s})\end{array}$ & $0.76 \pm 1.02$ & $0.82 \pm 0.82$ & $1.05 \pm 1.32$ & $0.64 \pm 0.59$ & $0.85 \pm 0.33$ \\
\hline $\begin{array}{l}\text { Average Maximum } \\
\text { Extensional } \\
\text { Strain Rate }\left(\mathbf{s}^{-1}\right)\end{array}$ & $1.13 \pm 0.18$ & $0.30 \pm 0.55$ & $0.20 \pm 0.31$ & $0.33 \pm 0.51$ & $0.03 \pm 0.01$ \\
\hline
\end{tabular}




\section{Measurement of thinning of some filaments during the pull}

To determine if produced filaments were being stretched (rather than being pulled out of the cell or growing in place), we assessed the thickness evolution of a subset of pulls using DIC microscopy. We have recently shown that the DIC edge intensity shift (DIC-EIS) across collagen fibrils is sensitive to changes in diameter ${ }^{45}$ and that the sensitivity is generally linear and proportional to the change in diameter. We took advantage of this capability to examine the relative change in the diameter of filaments during pull events. In the filaments that stayed in focus during the entire pull $(n=9)$, the DIC-EIS decreased at the onset of rapid contraction and tracked inversely with increases in pull velocity. Figure 3 shows thinning of a representative filament during the contraction. Supplemental Figure 1 demonstrates the thinning of four more filaments. While thinning as a function of stretching held for the measurements we made, there were many more filaments created by pulling than we could measure accurately. Thus, we cannot state with any certainty that all filaments thinned during the pulling events; indeed, there appear to be cases where filaments are formed from vesicular contents directly and likely do not thin with deposition.
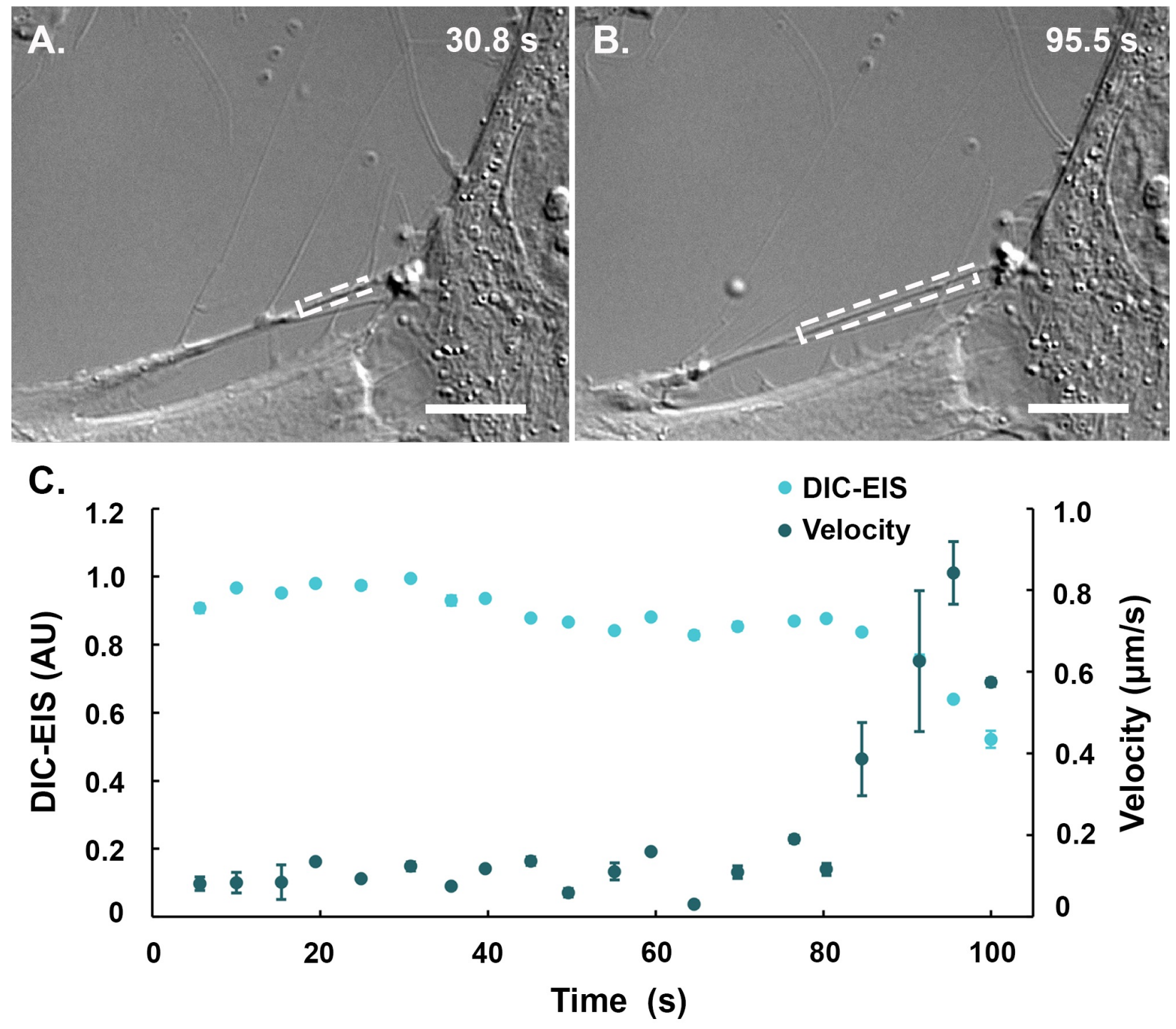
Figure 3. Thinning of the filaments during the Pull. Images showing the portion of the filament that was examined for thinning using DIC-EIS at to different time points $(A, B)$. Plot showing the DIC-EIS value versus the measured velocity at the time of the measurement (C). Scale Bar is $10 \mu \mathrm{m}$.

\section{Cells "bubble" during the pull}

Eighty years ago, Mary Stearns visualized ECM production by fibroblasts with her Camera Lucida and observed that cells exhibited surface bubbles (vesicles), often in locations where filaments form $^{18,19}$. During our data collection, we also observed that vesicles were released into the ECM just before and during contractions at the location of filament formation (Figure 4 and Supplemental Video 6). The bubbles disappeared shortly after exiting the cell and were replaced internally by new bubbles at the connection between cell surface/process and the forming filaments. We often saw an accumulation of bubbles immediately prior to the pull, and in some cases, they would shrink or disappear following the contraction. This suggests that the contents of the bubbles may have been ejected during the pulling event.

\section{Membrane surface curvature changes at the base of some filaments}

In some contraction events, we observed the cell surface attached to the forming filaments change in curvature. Figure 4 and Supplemental Video 7 clearly demonstrate this behavior, which is reminiscent of the "necking region" that was observed by Paten et al. 2016 during fibril pulling from the surface of droplets containing collagen (see Figure 1 in Paten et al. 2016 ${ }^{28}$ ). However, for some pulls, the filaments appeared to be directly attached to the cell surface, with no signs of membrane curvature or necking. The latter pulls were often cell surface pulls which generated a large number of filaments. 

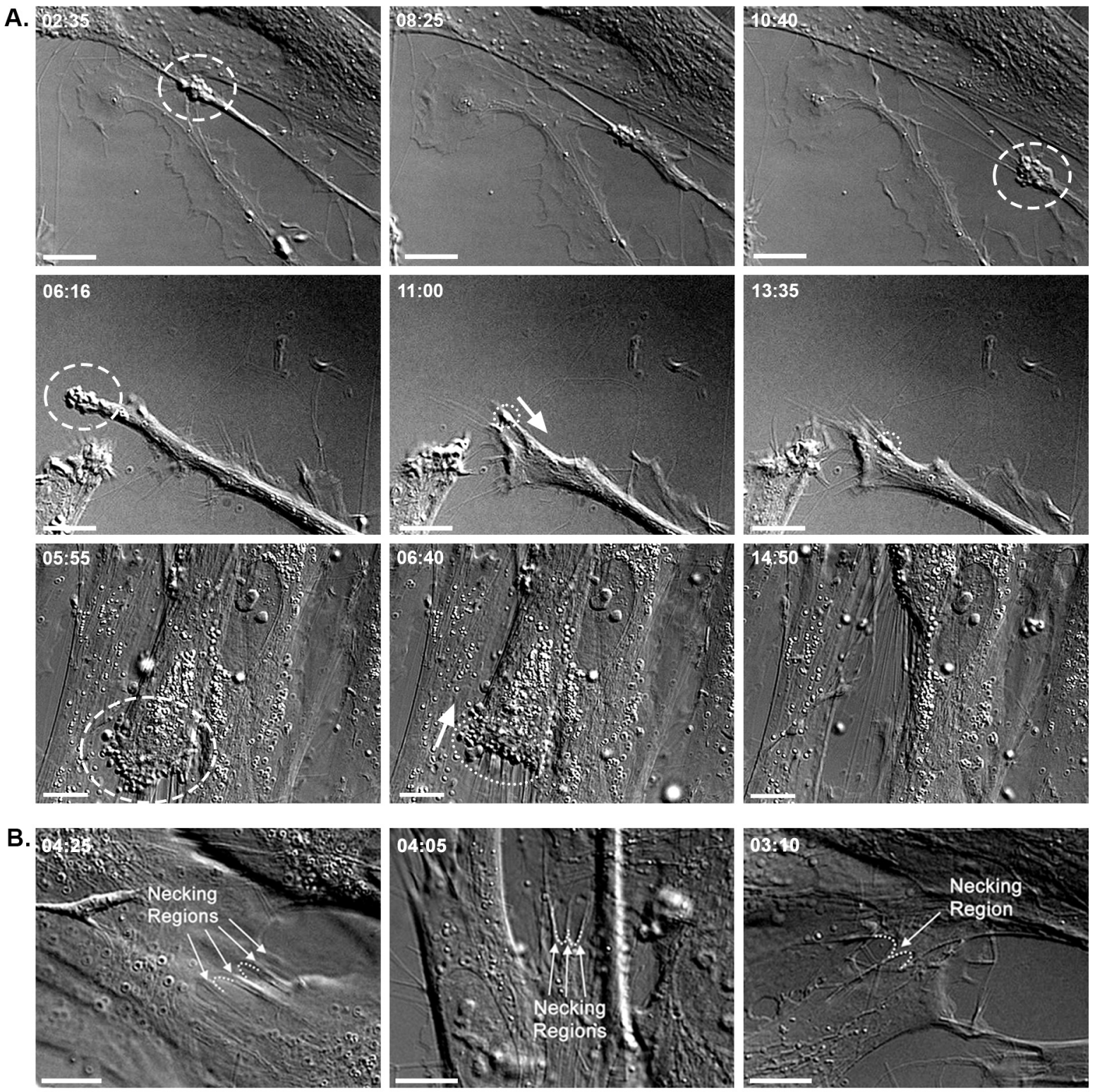

Figure 4. Cells bubbling during the pulling event (A). Dotted circles identify the bubbling regions and arrows show the direction of pull. Time is formatted as min:sec and corresponds to Supplemental Video 6 . B. Changes in cell surface curvature during the pulling event, corresponding to Supplemental Video 7 (B). The dotted lines and arrows identify the necking regions. All scale bars are $10 \mu \mathrm{m}$.

\section{Direct deposition of filaments on glass}

In some cases, we were able to closely observe the direct deposition of filaments on the glass surface. Supplemental Video 2 (Glass Pulls) and Supplemental Video 3 (Flat CP Pull 1 and Thick CP Pull 2) clearly show the deposition of material on the glass surface after a pulling event. In these cases, it appeared that the accumulation of vesicles was related to the material deposited, 
since the vesicles shrank and nearly disappeared after the pull was finished (Supplemental Video 6, Pull 4).

\section{Bidirectional pulls}

There were numerous cases observed (Supplemental Video 8) where the same cell would pull in one direction (typically along its principal axis) and then immediately pull at a different angle to the previous pull. In some cases, the angle was close to orthogonal. While this was not the rule, it suggested that there might be some internal bi-directionality or bi-polarization to these cells which, in this culture system ${ }^{43}$ and in their natural state, produce nearly-orthogonal sheets of collagen. It has been previously shown that cells from a particular tissue deposit matrix in culture in accordance with the tissue's native organization ${ }^{46}$.

\section{Filaments "reel in"}

In many pulling events, the filaments were not only extended by the retraction of the process that created them, but they were also "reeled in" at the same time, as seen in Supplemental Video 6, Pull 6. This makes the actual extensional strain rate of the filament higher than could be calculated by simply measuring the change in length of the filament.

\section{The effect of molecular crowding with Ficoll}

It has been shown that molecular crowding of fibroblasts in culture can convert secreted procollagen to telocollagen (i.e., activated for assembly ${ }^{47}$ ) and drastically enhance the rate of matrix deposition $^{48,49}$. We conducted this experiment with and without Ficoll as a molecular crowding agent. While the addition of Ficoll to the culture system resulted in thicker constructs at two weeks $20.38 \pm 5.81 \mu \mathrm{m}$ vs $12.95 \pm 1.71 \mu \mathrm{m}(\mathrm{p}<0.05)$, we did not observe significant differences in the types of pulls, maximum pull velocities, or maximum extensional strain rates during the initial four-day observation period in the crowded versus uncrowded experiments.

\section{Lateral association of adjacent filaments}

In some cases, a cell process could pull multiple filaments in close proximity with one another (see Supplemental Video 9). As the pull continued and filaments grew longer, they sometimes merged laterally from the cell process anchor point. The formation of multiple filaments from one narrow cell process provides evidence that these filaments formed extracellularly and were not formed intracellularly and then discharged.

\section{Availability of the raw data}

While we have made a reasonable effort to examine the videos regarding the formation of filaments via pulling events, we are very much aware that many more events related and unrelated to the formation of structure are ongoing in our cell culture system. The data set represents an extensive resource that is likely to be of interest to other researchers in the field of ECM development and cell behavior. We will thus make the raw videos, in NIS format, available to anyone who would like to examine them at the following repository: (TBD). Please use them well and cite this preprint or the subsequent journal article when/if published. Additionally, please place an acknowledgment that the videos were provided courtesy of Alexandra A. Silverman. 


\section{Discussion}

During the production of ECM for load-bearing and other organized connective tissues (e.g., cornea and sclera), creating highly-anisotropic arrays of fibrils is critical to the mechanical function of the tissue. The fibroblast cell, having long possessed contractile machinery and polarization, has a ready mechanism to drive and control ECM organization: mechanical force. Mechanical forces are vectors, with both direction and magnitude. They also can operate over long length and short time scales. Diffusion, another candidate driver of structure formation, is limited in its reach, directionality, and speed of action over long distances. It has thus been our contention that mechanical force is critical to the formation of the connective tissue anlagen, particularly in tissues where directionality or fibril anisotropy is critical to function ${ }^{50}$. Using our in vitro model of corneal stromal development, we demonstrate that persistent filamentous structures form secondary to the act of a cell or portion of a cell pulling towards itself. These pulls could involve one or multiple cells and different structures associated with each cell. Some of the pulls captured were of the highest velocities recorded in the literature for cell process retraction ${ }^{51}$ (to our knowledge) and some caused extensional strain rates well above those shown to produce collagen fibrils in vitro from cell-free, pure collagen solutions ${ }^{28}$. Though we often observed extensional strain rates at values much lower than those Paten et al. (2016) predicted were necessary to produce collagen fibrils, these pulls still produced persistent filaments. There are substantial implications about the underlying biophysics associated with this observation which require a more detailed knowledge of the molecular composition of the filaments, the proximal source of the molecules involved, and the distribution of strain on the forming filaments. Nonetheless, our observations here, performed at high spatial and temporal resolution (taking a photo every 5 seconds with a DIC detectability limit of $30 \mathrm{~nm}$ ) support our principal hypothesis that structures (filaments) are formed preferentially "along the lines of local mechanical strain." More succinctly, we have directly observed mechanical causation of biological structure at the cellular length scale. The active elements involved in the process appear to include cell surfaces, cell surface protrusions, lamellipodia, cell processes, and in many cases, vesicles (bubbles). The molecular milieu from which the filaments form remains in question, but likely involves HA, FN, and collagen, at least.

\section{Pulls are discrete events with characteristic kinematics capable of flow-induced protein aggregation or crystallization of biological polymers}

We label the events described in this study "pulls" to distinguish them from the normal movements of the cells. A pull is a rapid kinematic event that has a clearly characteristic motion generally comprising three parts: 1) The pull typically begins slowly as the pulling elements begin to stretch their attachments and build tension in the structures that connect the pulling cell to a collaborating cell or to the glass; 2) The pull accelerates to a peak retraction velocity, well above average cell velocity, and a peak extensional strain rate, ostensibly as more contractile elements engage and some resisting or connecting structures yield to the applied load and strain; 3) The pull then sharply declines in speed as the contractile elements bunch together, locally compacting the cell or cell process and halting the motion. Only some of the ultrafine pulls, which we believe were generating tunneling nanotubes, did not follow this pattern. Instead, they appeared to stretch continuously. Their average velocity was high, but their extensional strain rate was low (due to their length). For 
four of the pull categories, flat $\mathrm{CP}$, thick $\mathrm{CP}$, thin $\mathrm{CP}$, and cell surface pulls, the maximum extensional strain rates were sufficient to cause collagen fibril formation via FIC based on the data of Paten et al. $2016^{28}$ and well above that needed for hybrid collagen/FN fiber formation via combined FIA/FIC as shown in Paten et al. $2019^{41}$.

\section{All filaments observed during their production were derivative of pulling events between filament "anchor" points}

We note that we did not observe any filaments spontaneously forming in the culture system without an associated contraction event straining a precursor structure. Nor did we observe the pure extrusion of filaments from cell invaginations or filaments emerging from the cell surface in the absence of extensional mechanical assistance. All filaments started and ended at fixed points, either on a cell surface, a cell process or on the glass, suggesting that the initial connection between the surfaces that subsequently "separate" is an important mechanism to examine. Our data further suggest that filaments are not being drawn, pre-formed out of the cell and indeed can arise far from the main body of the cell in association with extended processes (Supplemental Video 10). In some cases, filaments grew to lengths longer than the cell body, providing further evidence that the filament was forming, growing, or stretching as a direct result of the pull. The videos suggest that cooperation between cells is critical to filament formation. Data on collagen fibril synthesis support this idea. Lu et al. (2018) reported that individual collagen fibrils are formed by more than one cell when they used co-cultures of two different colored collagen expressing cells (mCherryand GFPtpz-collagen) ${ }^{8}$. Our observations support their results and demonstrate contractionmediated formation of filaments where the molecules are likely sourced by multiple cells in contact with one another. DIC-EIS measurements of filament thickness suggest thinning of some filaments during pulls, supporting the hypothesis that filaments were often stretched, as opposed to being formed intracellularly and deposited into the ECM. However, our DIC-EIS analysis was performed on a small subset of the filaments formed and we cannot conclude that all filaments thinned during stretching or that the thinning was the result of a volume conserved stretching of a precursor structure. Indeed, there are some instances where filaments appear to be produced from materials lost from adjacent vesicles. If this were the case, then the filaments are either unraveled or formed directly from the opening of the vesicle to the extracellular space.

Finally, we did observe that some filaments were being drawn back into the cell process or "reeled in" as they were being formed and lengthened. From electron microscope micrographs of developing tendon and cornea, Trelstad and Birk ${ }^{2}, 52$ argued that collagen fibrils are formed intracellularly and discharged into the ECM. However, Ten Cate and co-workers ${ }^{53-58}$ showed that the presence of intracytoplasmic fibrils are evidence for the ability of fibroblast cells to phagocytose their own product in rapidly remodeling tissues (reviewed by Siadat $(2020)^{59}$, but study of the original text is strongly recommended). Furthermore, it has been shown that intracellular collagen fibrils are present even when collagen synthesis is blocked ${ }^{60-62}$ and that cytoplasmic actin filament systems are involved in the phagocytosis of collagen ${ }^{60,63}$. While our data clearly demonstrate that filaments are formed extracellularly, we suspect that 1) some filaments are lengthened by being reeled in by cell processes and 2) in some cases if filaments 
break from one of their anchor points, they will be phagocytosed after being reeled in (probably similar to those that were seen by Ten Cate and co-workers).

\section{Filament type and composition}

Based on observations from our movies, there appear to be multiple filament types produced by the system: 1) Filaments appear to be formed by stretching of the cell membrane; 2) Filaments appear to be pulled directly through the cell body surface, possibly straight out of vesicles; 3 ) Filaments appear to be drawn from vesicles at the tips of cell processes; and 4) "Tunneling nanotubes" appear to be formed between cells ${ }^{64}$ (indicated by the clearly visible shuttling of "gondolas" between cells) (Supplemental Video 11). There are many possible candidate materials involved in the filaments we observed. Each of these have important consequences regarding the ultimate formation of durable structure by the fibroblasts in this system. We are currently working to identify the composition of the filaments, but they are quite fragile and do not survive processing for standard immunohistochemistry. Based on a review of the literature and our knowledge of the corneal fibroblast secretome in this system, filaments likely comprise HA, FN, and/or collagen (all known to be present in fibroblast culture systems) or are an extension of cell membrane (with attendant receptors for all three molecules). Hyaluronan-rich pericellular protrusions are highly sensitive to fixation and dehydration ${ }^{65,66}$. We suspect that the filaments observed in this study were hyaluronan-rich since they were extremely sensitive to sample processing, but they likely also contain both FN and collagen in a fragile state of aggregation.

\section{Proposed models of ECM filament formation}

Given the limitations of our observations, it is impossible to draw conclusions about the precise physicochemical mechanisms behind the formation of the filaments. However, it is possible to propose some potential mechanisms based on our knowledge of the cell system, the materials involved, the kinematics, and polymer biophysics. Nonetheless, it is quite clear that mechanical strains and forces play a critical role in the process we observed in this system. We propose two possible models of ECM filament formation driven by cellular contractions (Figure 5). Both of the models assume that ECM elaboration occurs in a cell-dense, molecularly-crowded environment (unlike our system which was open) and that the cellular kinematics we observed carry on even as the cell culture becomes confluent. Because all filaments were formed by the mechanical separation of two structures, both of our models begin with the formation of an attachment between cells (Figure 5A, 5D). 
Model 1
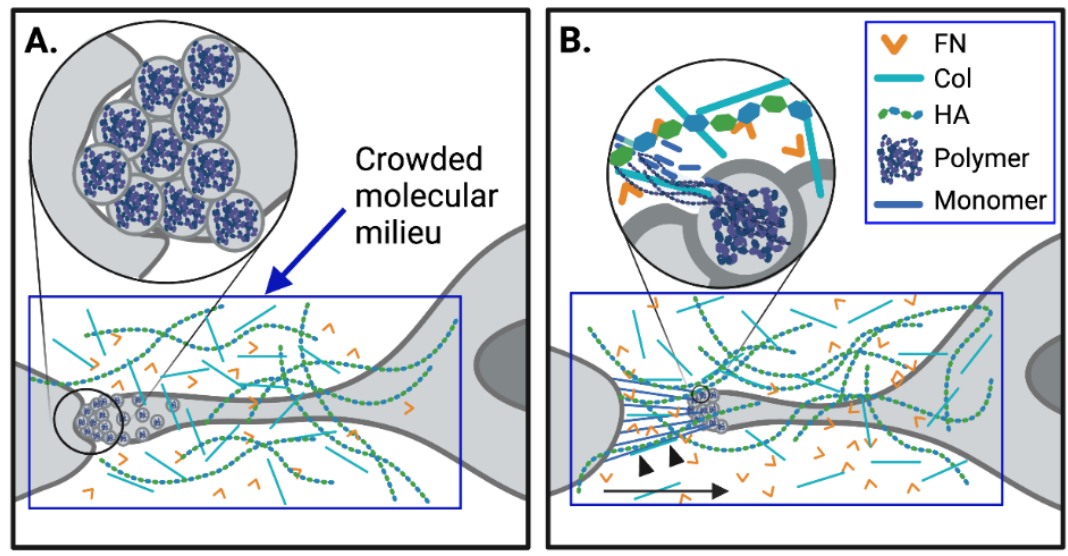

Model 2
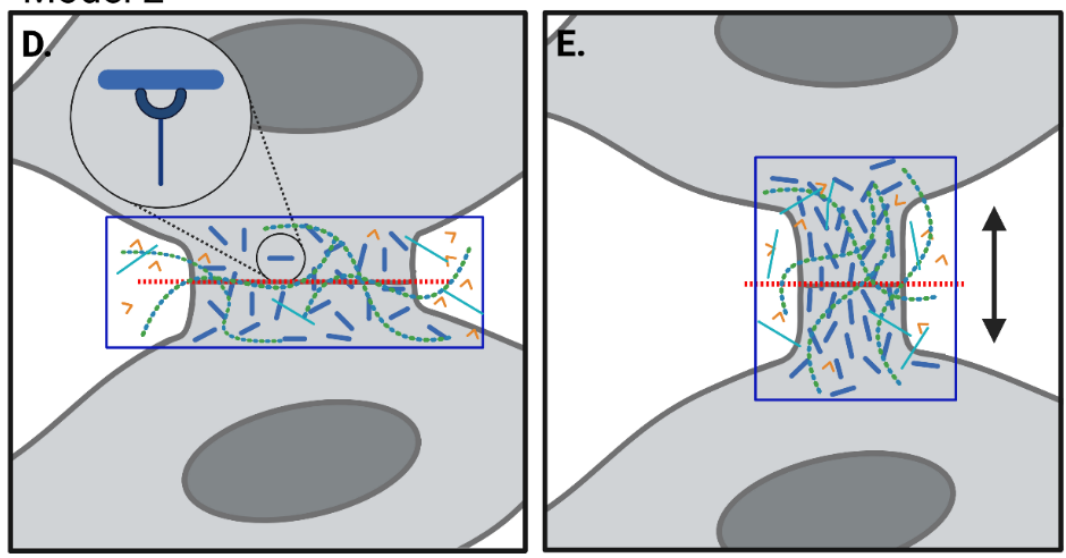
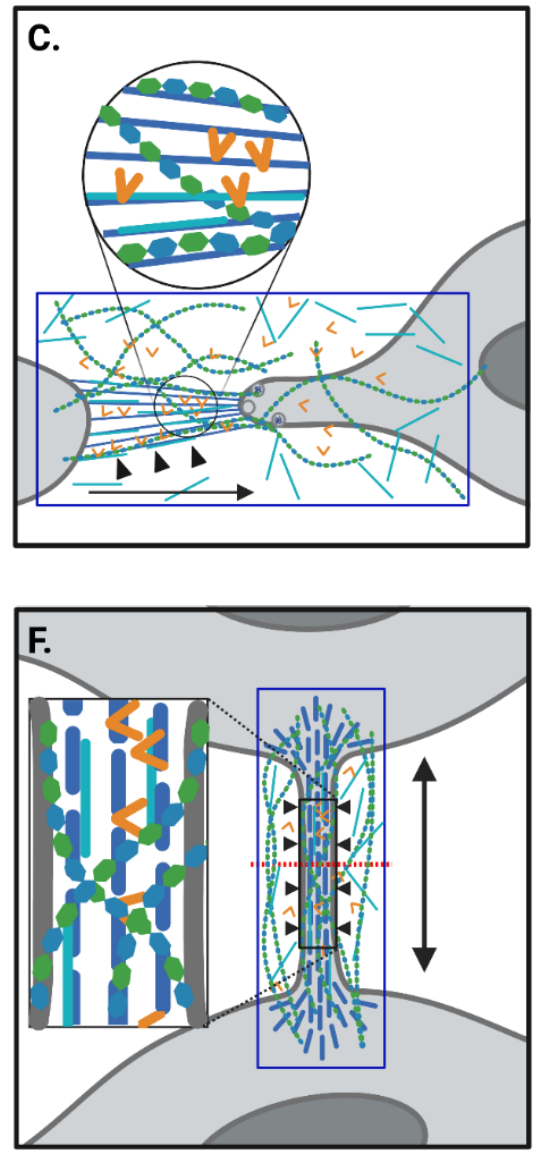

Figure 5. Two proposed models for mechanically driven filament assembly. Proposed sequence of events for Model 1 in which the separating cell processes/bodies remain connected by polymerizing/aggregating precursor biopolymers (A-C). Proposed sequence of events for Model 2 in which the cells remain connected together by a thinning process on which precursor biopolymer molecules bind, concentrate, extend, and align during the pull (D-F). In both models, cell adjacent molecules are able to participate in the filament forming process. Fibronectin (FN), Collagen (Col), Hyaluronan (HA). See text for full details. Image was created with Biorender.com.

Model 1: Pure FIA/FIC. In the first model (Figure 5 A-C), filaments are generated without a cell membrane extension at their core. We believe that we see these types of filaments forming at the tips of thick cell processes or drawn directly from the cell surface during contraction events. The attachment point is formed such that biopolymer precursor molecules in dense solution are positioned between the two surfaces (Figure 5A shows precursor packed into vesicles at the attachment point). Upon pulling, the dense solution with its precursor biopolymers is stretched, rapidly forming filaments (Figure 5B shows the initial stretch and depicts the polymers "spooling" out of the vesicles as filaments). The physics of stretching a self-assembling, polymer-filled solution can drive assembly of the polymers into long aggregates or crystals ${ }^{33}$. As the stretching progresses, the dense molecular milieu outside the cells (pre-synthesized or concurrently ejected from vesicles) may participate in the filament composition (Figure 5C). While we do not currently know the proximal source or composition of molecules, a dense mix of structural biopolymer molecules, including HA, FN, and collagen, is known to be present during ECM elaboration. All of these molecules all are known to assemble into fibers, with FN and collagen known to assemble 
under extensional strain ${ }^{28,29}$. A mixture of HA, FN, and collagen would be an excellent candidate flow-induced multi-polymeric assembly system. In this system, we propose that exceedingly long HA molecules would first readily flow-aggregate into "cables" ${ }^{\prime \prime 7}$ under lower extensional strain. Then FN bound to the stretching HA would unfold and assemble into filaments, and collagen, caught in or on the stretching HA/FN filament, would align and assemble into fibrils ${ }^{68}$ (which is the last and most important step in durable ECM formation). The key drivers of assembly would be the stretching and the capturing of the molecules on the extending filament in the dense macromolecular milieu. However, there are many variables here about which we know very little. In particular, we do not understand how the attachments form, what causes the contraction timing, and how/when the structural biopolymer molecules arrive (or if they are just in local abundance). The presence of vesicles suggests that there is a source of concentrated material close by. It is known that HA is synthesized by HAS $-2^{69}$ near the membrane. We also know that pro-collagen is exported to the surface in secretory granules ${ }^{70}$ and that it (and its pro-peptidases) is potentially bound to FN to facilitate local activation ${ }^{71}$.

Model 2: Cell Process/Receptor Mediated FIA/FIC. In the second model (Figure 5D-F), the stretching filament, at its center, has a long thin cell surface extension replete with cell surface receptors that bind the structural biopolymers, forcing them into alignment and into close approximation circumferentially as the filament extends. We believe these types of filaments form often in the flat pulls and in some of the thin process pulls. All three of our candidate molecules are ligands for cell receptors found on corneal and other fibroblasts (HA-CD44 ${ }^{72,73}$; FN: $\alpha 5 \beta 1^{74}$; and Col: $\alpha 2 \beta 1^{75}$ ), further, there is evidence of molecular interactions between HA, FN, and collagen during filament formation ${ }^{68}$. The cell/cell attachment in the second model forms (Figure 5D) but does not separate. Instead, the contraction causes the cell membrane(s) to stretch into long thin processes (Figure 5E and F). In the crowded environment, the membrane is likely bound to one or more of the available structural biopolymers, reducing their mobility and increasing their effective relaxation time. As the stretch continues, the surface bound molecules are forced to extend in the direction of load (Figure 5E) and concentrated circumferentially as the filament thins (Figure 5F: arrowheads). The effect of the combined extensional stretch and binding produces physical conditions that should promote the lateral aggregation or crystallization of polymers associated with the surface of the process. The second model is consistent with the co-alignment of corneal cell processes ("keratopodia") with collagen arrays observed by Young et al. ${ }^{5}$ and Bueno et $a l^{76}$.

We note that both of these models are rudimentary and lack important details. There remains plenty of physics and chemistry left to tease apart if either or both models are representative.

The Role of HA in Filament Formation. In our proposed models, HA, with its long contour length, is likely to play a critical filament-initiator role. Based on previous investigations, we suspect there is a cascade of hyaluronan-related events that lead to accumulation of FN and collagen near cell surface and cell processes, followed by structure-forming cellular contractions. The contractions must result in FIA or FIC because the filaments produced exceed the length of all the molecules involved and are thus discontinuous aggregates formed by pulling. However, HA, with its massive molecular weight and length, is particularly amenable to FIA, even at low extensional strain rates. 
This might be why all pulls were productive events that created structures, even at lower extensional strain rates than predicted by Paten et al. $(2016)^{28}$. We thus believe HA is critical in the early stages to initiate the FIA process.

\section{Limitations of the experiment}

Limited physiological relevance of early cultures on glass. While we have been able to observe a substantial number of events in great detail, we have indeed sacrificed some physiological validity to do so. The experimental model is a human primary cell culture system that is known to produce orthogonal arrays of collagen in an arrangement similar to the native cornea stroma over time. Typically, the cells produce an abundant collagen matrix after reaching confluency and forming multiple layers, which takes about one week. Prior to forming confining layers, the cells cannot produce matrix effectively (likely because the collagen produced floats away into the media prior to conversion by propeptidase ${ }^{77}$ ) and they behave more like myofibroblasts than fibroblasts until they reach confluency. Unfortunately, when the system becomes crowded with cells and matrix, our label-free DIC imaging suffers clarity loss from interfering structures. Molecular composition of filaments and involved structures is unknown at this time. In addition, we are unable to identify precisely what molecules are in or on the filaments, vesicles or bound to the involved surfaces. Post-fixation washing for immunohistochemistry resulted in the loss of these rather fragile filamentous structures. We made several attempts to fix and label the cells in situ on the microscope and watched as the filaments disappeared with successive processing steps. We altered procedures to minimize damage, but ultimately had to abandon the effort (for now). We have begun using live stains and will report on our findings in due course. Culture system contains FBS. There are potentially interfering effects of FN in the system due to the presence of bovine serum in the media.

\section{Implications of the observed behavior}

There are a number of potential implications for ECM development, growth, maintenance repair and pathology if we cautiously extend the fundamental pulling behaviors observed in our model system to the in vivo cell-ECM relationship (see our statement of limitations for the experiment listed above). Previous developments linking mechanics directly to biopolymer assembly in conjunction with the observations from this investigation invite us to adjust some of our ideas about biological structure formation.

Force-Structure Causality. The first implication is the potential discovery of the proximal mechanism driving organized ECM production, which we posit to be mechanochemical in nature. In all cases we observed, pulling produced the filaments. We describe this activity as mechanical causation of structure, or more formally, mechanochemical force-structure causality (MFSC). Mechanical strain has previously been shown to cause structure formation for two of the three major structural biopolymers typically involved in the development of ECM: $\mathrm{FN}^{78}$ and collagen ${ }^{28}$. Fibrillar structures form from these molecules as mechanical strains lower the activation energy barrier to self-assembly. In MFSC, mechanical input directly alters the chemical behavior of the polymers. In the case of $\mathrm{FN}$, the deformation of the molecules opens a cryptic binding site to promote FN fiber assembly via FIA $^{78}$. For collagen, strain-rate induced alignment of collagen 
molecules accelerates lateral assembly to produce fibrils via $\mathrm{FIC}^{28}$. When $\mathrm{FN}$ and collagen are present and strained together, there is a synergistic effect and the energy barrier to collagen fibril assembly is lowered further ${ }^{41}$. The third component molecule, HA, with its very long contour length ( $20 \mathrm{um})$ and thus long molecular relaxation time, is also an excellent candidate for FIA as it does not need very high extensional strain rates to molecularly align with applied strain and it is known to form filaments or "cables"67. The most important aspect of MFSC is that structure is formed directly in the path of the forces that create it, ostensibly to resist subsequent forces which propagate along the same direction. This is possibly why we first see cell and cell process alignment with the eventual matrix that is formed in developing organized tissues ${ }^{2,5,52,79}$. Our theory here is that the cells produce the initial structure along lines of "pull" and then global level tissue forces (i.e., muscle contractions, growth pressure increases) complete the structure formation as we described in Paten et al. $(2016)^{28}$. It has been shown that knocking out non-muscle myosin II disrupts collagen fibril formation ${ }^{26}$, abrogating muscle contractions cause tendon formation to fail ${ }^{37-40}$, and de-pressuring the ocular globe leads to impaired growth ${ }^{80}$, which suggest that local and global mechanical forces are central to ECM structure formation.

Filament Deposition under Tension. Tissues generally exhibit prestress and some growth and remodeling models require fibril deposition under tension ${ }^{81}$. MFSC supports this idea inherently. If mechanical strains are required to cause the formation of structure, then the structures that are formed are going to be pre-strained by design. It is interesting to note that the seminal demonstration of engineered tissue formation was a collagen gel contracted by fibroblasts ${ }^{82}$.

Soft vs. Hard Substrates and the Effect of Load. If the formation of tissue requires contraction by cells, then the stiffness (and effective stiffness) of the substrate in which they reside is an important factor in their force generating ability. Our cells were plated on glass which is, in effect, infinitely stiff and thus, would be able to generate maximum force and velocities provided they were well anchored to the substrate. We expect that on a very soft material, however, the cells would not be able to generate the same separation forces or speeds, and thus be limited in their ability to produce effective pulls, and consequently, filaments. By the same reasoning, fibroblasts on loaded soft tissues, would experience an effectively higher resistance in the direction of force and would likely be more effective at producing structure precisely where the loads are higher and in the direction of higher strain.

Effect of Cell Polarization. Because the formation of filaments occurs along the lines of pull, the direction of cell polarization is possibly important to the final formation of ECM in the developing tissue. In our system, we used corneal stromal cells which inherently produce arrays of fibrils in two directions and at about a 90-degree angle between arrays. We found many examples of double pulls where cells would pull in one direction and then follow that by pulling in another direction, which was often close to orthogonal. Electron micrographs ${ }^{2}$ and reconstructions ${ }^{5}$ of developing chick cornea show that the same cell has collagen fibrils extending in two directions from the cell body. Therefore, multiple pulling directions could be fundamental to the ultimate organization of the tissue being constructed.

Fibrosis and Wound Healing. Nearly $45 \%$ of all deaths worldwide are related to some form of fibrosis ${ }^{83}$. It is well-known that increased contractile machinery is present in myofibroblasts and 
that the transformation of local fibroblasts to myofibroblasts is a marker of the progression to fibrosis $^{84}$. If MFSC is a viable theory, we expect that the increased contractile machinery would cause the formation of pathogenic structure, provided there were available precursor biopolymers. Further, once stiffer structures are produced, the effectiveness of each pulling event would be enhanced, leading to an accumulation of material. The good news is that once we understand the incipient mechanisms of fibrosis, there are opportunities to control or reverse it. For example, one could target and locally silence the contractile machinery, such as the receptors that permit fibril attachment, or the production of precursor biopolymers (HA, FN, or collagen). Detensioning the fibrotic region would also help (e.g., for surface scarring). For wound healing, it would be important to promote fibrosis in a controlled way. MFSC suggests multiple ways that wound healing could be enhanced, most of which are the reverse of what we could do to reduce fibrosis.

\section{Conclusion}

Our data suggest that local pulling leads directly to structure formation in an in vitro model of developing ECM. The nature of the pulling profile indicates that the pulls are events separate and distinct from those that provide cell motility or apply tension in general. Tying mechanical force and the resulting strain rates directly to biopolymer structure formation via FIA and FIC could lead to a clearer functional understanding of the cell-matrix interplay during development, growth, and pathological changes of connective tissues (e.g., fibrosis). As we have pointed out, there are rather important implications associated with the proposed MFSC model. However, on a more philosophical note, if millions of micron-scale, cooperative cell contractions cause the formation of tiny strings that integrate to form our load-bearing structure then we could be, quite literally, "pulled" into existence.

\section{Methods}

\section{Cell Isolation and Culture}

PHCFs were isolated from 74-year-old human donor corneas (obtained through the National Disease Research Interchange) following the procedure established by Bueno et al. (2009) ${ }^{76}$. Briefly, donor corneas were gently scraped of their epithelium and endothelium to ensure only stromal cells were isolated. Then, the corneas were cut into $2 \times 2 \mathrm{~mm}$ pieces and sterilized by soaking in 1X Gibco phosphate buffered saline (PBS) (Fisher Scientific, 10-010-023) containing $1 \%$ HyClone penicillin streptomycin 100X solution (Fisher Scientific, SV30010) and 0.1\% amphotericin B $250 \mu \mathrm{g} / \mathrm{mL}$ solution (Sigma Aldrich, 1397-89-3). Each explant was adhered to the center of a 6-well culture plate (Corning, 3516) and PHCF were cultured using the reagents and techniques established by Siadat et al. $(2021)^{85}$. Complete media, comprising Corning DMEM with L-glutamine and $4.5 \mathrm{~g} / \mathrm{L}$ glucose without sodium pyruvate (Fisher Scientific, MT10017CV), $1 \%$ penicillin streptomycin, $0.1 \%$ amphotericin $\mathrm{B}$, and $10 \%$ Corning regular fetal bovine serum (Fisher Scientific, MT35010CV), was gently added to the well. A half media exchange was performed every 3-5 days until the PHCF migrated off the explant. Once confluent, the explants were discarded and PHCF were expanded and frozen for future use. 


\section{Live-Cell Imaging}

PHCF were seeded on uncoated, 1.5 thickness glass-bottomed, temperature-controlled culture dishes (Bioptechs, 04200417B) at passage 3 at a concentration of $10,000 \mathrm{cells} / \mathrm{cm}^{2}$. On day 1, a full media exchange was performed and $\mathrm{CO}_{2}$-infused, complete media containing $0.5 \mathrm{mM} \mathrm{L}-$ ascorbic acid (Sigma Aldrich, A4544) was added to stabilize the collagen produced by the culture. For half the samples, $37.5 \mathrm{mg} / \mathrm{mL}$ Ficoll 70 (Sigma Aldrich, F2878) and $25 \mathrm{mg} / \mathrm{mL}$ Ficoll 400 (Sigma Aldrich, F8016) was added to the media to increase the molecular crowding of ECM proteins. 6 samples treated with only ascorbic acid and 6 samples treated with ascorbic acid, Ficoll 70, and Ficoll 400 were assessed.

After the media was exchanged, the cells were incubated for 3 hours and then imaged with a coverglass lid (Bioptechs, 4200312) using a Nikon ECLIPSE TE2000-E inverted microscope. A 60X Nikon CFI Apochromat TIRF oil objective and Photometrics CoolSNAP EZ CCD camera was used to take high-resolution, DIC photos every 5 seconds for one hour. The Nikon perfect focus system was utilized to ensure the sample remained in focus during imaging. To keep the sample at $37{ }^{\circ} \mathrm{C}$, an objective heater (Bioptechs, 150819), a microscope stage adapter (Bioptechs, 04202602), an objective heater controller (Bioptechs, 150803), and a culture dish temperature controller (Bioptechs, 0420-04-03) were used. All samples were imaged at approximately the same location to ensure a consistent distribution of cells.

After imaging the sample, it was placed back in the incubator to be subsequently imaged on day 2, 3, and 4. On days 2 and 4, no media exchange was performed prior to imaging. On day 3, a full media exchange was performed 3 hours prior to imaging using $\mathrm{CO}$ 2-infused complete media containing either only $0.5 \mathrm{mM} \mathrm{L}$-ascorbic acid or $0.5 \mathrm{mM} \mathrm{L}$-ascorbic acid, $37.5 \mathrm{mg} / \mathrm{mL}$ Ficoll 70 , and $25 \mathrm{mg} / \mathrm{mL}$ Ficoll 400.

\section{Assessing Cell Culture Thickness}

After imaging on day 4, samples were grown until day 14 with full media exchanges every 2-3 days using complete media with consistent concentrations of either only L-ascorbic acid or Lascorbic acid, Ficoll 70, and Ficoll 400. On day 14, cell construct thickness was assessed by using the Nikon inverted microscope with the $60 \mathrm{X}$ oil objective and DIC to perform a Z-scan in center, north, south, east, and west locations in each cell culture. Multiple locations were used due to heterogeneity in the cell culture; these locations were averaged to obtain an average thickness for each cell construct.

\section{Time-Lapse Analysis}

Time-lapse videos were analyzed frame-by-frame using FIJI. For each identified pull, the length of the persistent filament formed was measured over time, and the following equations were used to analyze the pulling events:

PHCF pull velocity: $v_{n}=\frac{L_{n}-L_{n-1}}{t_{n}-t_{n-1}}$ 
PHCF pull extensional strain rate: $\varepsilon_{n}=\frac{\left(L_{n}-L_{n-1}\right) / L_{n-1}}{t_{n}-t_{n-1}}$

Where $L_{n}$ is the length of the persistent filament in frame $n, L_{n-1}$ is the length of the persistent filament in the previous frame $(n-1), t_{n}$ is the time in frame $n$, and $t_{n-1}$ is the time at the previous frame. Though our microscope was set to take photos every 5 seconds, this timing was not always precise, and images were taken approximately every 4-6 seconds. For our analysis, we used the exact time points exported from our data.

A total of 130 pulling events were analyzed, individually by three authors to obtain 3 measurements for length, 3 measurements for velocity, and 3 measurements for extensional strain rate for each pull at each time point. These values were averaged to obtain a mean length, velocity, and extensional strain rate for each pull at each time point. The maximum velocity and extensional strain rate for each pulling event was used to compare events.

Pulling events were subsequently categorized into five pull types based on pull morphology. For pulling events that created multiple persistent filaments, we recorded the total number of filaments created and their maximum length, and then analyzed the most prominent and visible filament. The length of the contracting cell process and its average thickness was recorded. To determine cell process thickness, measurements were taken at 5 locations along the process and then averaged. For each pulling event, it was noted if the cell process contained a bubbling footpad that released vesicles into the extracellular space. It was also recorded whether the event occurred between two cells, or one cell and the glass surface of the culture dish.

\section{DIC-EIS Analysis}

Filament diameter change was estimated from DIC images based on a method that measures collagen fibril diameter ${ }^{45}$. Only filaments that stayed in focus during the entire pulling event were analyzed. DIC images were uploaded into Matlab. A rectangular region of interest was defined along the middle section of each filament. DIC-EIS was calculated as the average difference between the maximum and minimum intensities across each filament.

\section{Video Creation}

Files were imported into FIJI as an image sequence and cropped, rotated, and adjusted to have increased contrast and better showcase the pulling event. The scale bar and time stamp were also added in FIJI. Our time stamp was set to increase in increments of 5 seconds, since each photo was taken every 5 seconds on average. Photoshop was utilized to create video annotations and iMovie was used to assemble and edit the videos.

\section{Acknowledgements}

This work was supported by funding from NIH/NEI 1R21EY029167. 


\section{$\underline{\text { References }}$}

1. Musiime, M., J. Chang, U. Hansen, K.E. Kadler, C. Zeltz, and D. Gullberg, Collagen Assembly at the Cell Surface: Dogmas Revisited. Cells, 2021. 10(3): p. 662.

2. Birk, D.E. and R.L. Trelstad, Extracellular compartments in matrix morphogenesis: collagen fibril, bundle, and lamellar formation by corneal fibroblasts. J Cell Biol, 1984. 99(6): p. 2024-33.

3. Birk, D.E., E.I. Zycband, D.A. Winkelmann, and R.L. Trelstad, Collagen fibrillogenesis in situ: fibril segments are intermediates in matrix assembly. Proc Natl Acad Sci U S A, 1989. 86(12): p. 4549-53.

4. Birk, D.E., E.I. Zycband, S. Woodruff, D.A. Winkelmann, and R.L. Trelstad, Collagen fibrillogenesis in situ: fibril segments become long fibrils as the developing tendon matures. Dev Dyn, 1997. 208(3): p. 291-8.

5. Young, R.D., C. Knupp, C. Pinali, K.M. Png, J.R. Ralphs, A.J. Bushby, T. Starborg, K.E. Kadler, and A.J. Quantock, Three-dimensional aspects of matrix assembly by cells in the developing cornea. Proc Natl Acad Sci U S A, 2014. 111(2): p. 687-92.

6. Guo, X., A.E. Hutcheon, S.A. Melotti, J.D. Zieske, V. Trinkaus-Randall, and J.W. Ruberti, Morphologic characterization of organized extracellular matrix deposition by ascorbic acid-stimulated human corneal fibroblasts. Invest Ophthalmol Vis Sci, 2007. 48(9): p. 4050-60.

7. Saeidi, N., X. Guo, A.E. Hutcheon, E.A. Sander, S.S. Bale, S.A. Melotti, J.D. Zieske, V. Trinkaus-Randall, and J.W. Ruberti, Disorganized collagen scaffold interferes with fibroblast mediated deposition of organized extracellular matrix in vitro. Biotechnol Bioeng, 2012. 109(10): p. 2683-98.

8. Lu, Y., et al., Live Imaging of Type I Collagen Assembly Dynamics in Osteoblasts Stably Expressing GFP and mCherry-Tagged Collagen Constructs. J Bone Miner Res, 2018. 33(6): p. 1166-1182.

9. Zareian, R., et al., Human Corneal Fibroblast Pattern Evolution and Matrix Synthesis on Mechanically Biased Substrates. Tissue Eng Part A, 2016. 22(19-20): p. 1204-1217.

10. Baitsell, G.A., A study of the development of connective tissue in the amphibia. American Journal of Anatomy, 1921. 28(3): p. 447-475.

11. Baitsell, G.A., Memoirs: On the Origin of the Connective-Tissue Ground-Substance in the Chick Embryo. Journal of Cell Science, 1925. 2(276): p. 571-589.

12. Baitsell, G.A., The origin and structure of a fibrous tissue formed in wound healing. Journal of Experimental Medicine, 1916. 23(6): p. 739-756.

13. Hertzler, A.E., Pseudoperitoneum, Varicosity of the Peritoneum and Sclerosis of the Mesentery: with a Preliminary Note on Development of Fibrous Tissue. Journal of the American Medical Association, 1910. 54(5): p. 351-356.

14. Baitsell, G.A., The origin and structure of a fibrous tissue which appears in living cultures of adult frog tissues. The Journal of experimental medicine, 1915. 21(5): p. 455-478.

15. Isaacs, R., An interpretation of connective tissue and neurogliar fibrillae. Anat. Record, Phila., x, 1916. 206.

16. Isaacs, R., The structure and mechanics of developing connective tissue. The Anatomical Record, 1919. 17(4): p. 242-270.

17. Ferguson, J.S., The Behavior and Relations of Living Connective Tissue Cells in the Fins of Fish Embryos with Special Reference to the Histogenesis of the Collaginous or White Fibers. The American Journal of Anatomy, 1912. 13: p. 129. 
18. Stearns, M.L., Studies on the development of connective tissue in transparent chambers in the rabbit's ear. I. American Journal of Anatomy, 1940. 66(1): p. 133-176.

19. Stearns, M.L., Studies on the development of connective tissue in transparent chambers in the rabbit's ear. II. Developmental Dynamics, 1940. 67(1): p. 55-97.

20. Wolbach, S.B., Controlled Formation of Collagen and Reticulum. A Study of the Source of Intercellular Substance in Recovery from Experimental Scorbutus. Am J Pathol, 1933. 9(Suppl): p. 689-700 5.

21. Wolbach, S.B. and P.R. Howe, Intercellular Substances in Experimental Scorbutus. Arch. of Path. \& Lab. Med., 1926. 1(1).

22. Li, S., C. Van Den Diepstraten, S.J. D'Souza, B.M. Chan, and J.G. Pickering, Vascular smooth muscle cells orchestrate the assembly of type I collagen via alpha2betal integrin, RhoA, and fibronectin polymerization. Am J Pathol, 2003. 163(3): p. 1045-56.

23. Johnson, C. and Z.S. Galis, Quantitative assessment of collagen assembly by live cells. J Biomed Mater Res A, 2003. 67(3): p. 775-84.

24. Sottile, J. and D.C. Hocking, Fibronectin polymerization regulates the composition and stability of extracellular matrix fibrils and cell-matrix adhesions. Mol Biol Cell, 2002. 13(10): p. 3546-59.

25. Canty, E.G., T. Starborg, Y. Lu, S.M. Humphries, D.F. Holmes, R.S. Meadows, A. Huffman, E.T. O'Toole, and K.E. Kadler, Actin filaments are required for fibripositormediated collagen fibril alignment in tendon. Journal of Biological Chemistry, 2006. 281(50): p. 38592-38598.

26. Kalson, N.S., T. Starborg, Y. Lu, A. Mironov, S.M. Humphries, D.F. Holmes, and K.E. Kadler, Nonmuscle myosin II powered transport of newly formed collagen fibrils at the plasma membrane. Proc Natl Acad Sci U S A, 2013. 110(49): p. E4743-52.

27. Kapacee, Z., S.H. Richardson, Y. Lu, T. Starborg, D.F. Holmes, K. Baar, and K.E. Kadler, Tension is required for fibripositor formation. Matrix Biol, 2008. 27(4): p. 371-5.

28. Paten, J.A., S.M. Siadat, M.E. Susilo, E.N. Ismail, J.L. Stoner, J.P. Rothstein, and J.W. Ruberti, Flow-Induced Crystallization of Collagen: A Potentially Critical Mechanism in Early Tissue Formation. ACS Nano, 2016. 10(5): p. 5027-40.

29. Ejim, O.S., G.W. Blunn, and R.A. Brown, Production of artificial-orientated mats and strands from plasma fibronectin: a morphological study. Biomaterials, 1993. 14(10): p. 743-748.

30. Siadat, S.M., Surface Viscometry of an Evaporating Droplet Containing a Protein (Collagen) as a Function of Time and Depth2015: Northeastern University.

31. Rao, I. and K. Rajagopal, A study of strain-induced crystallization of polymers. International Journal of Solids and Structures, 2001. 38(6-7): p. 1149-1167.

32. Keller, A., Flow-Induced Orientation and Structure Formation. In Proc, Polymers. Materials science and technology: a comprehensive treatment, 1997. 18: p. 189-268.

33. Mackley, M. and A. Keller, Flow induced polymer chain extension and its relation to fibrous crystallization. Philosophical Transactions of the Royal Society of London. Series A, Mathematical and Physical Sciences, 1975. 278(1276): p. 29-66.

34. Liu, C., N. Morimoto, L. Jiang, S. Kawahara, T. Noritomi, H. Yokoyama, K. Mayumi, and K. Ito, Tough hydrogels with rapid self-reinforcement. Science, 2021. 372(6546): p. 10781081.

35. Dobson, J., et al., Inducing protein aggregation by extensional flow. Proceedings of the National Academy of Sciences, 2017. 114(18): p. 4673-4678. 
36. Hosseini, H., A. Rangchian, M. Prins, C. Giza, J. Ruberti, and H. Kavehpour, Probing Flow-Induced Biomolecular Interactions With Micro-Extensional Rheology: Tau Protein Aggregation. Journal of Biomechanical Engineering, 2020. 142(3): p. 034501.

37. Peterson, B.E., R.A. Rolfe, A. Kunselman, P. Murphy, and S.E. Szczesny, Mechanical Stimulation via Muscle Activity is Necessary for the Maturation of Tendon Multiscale Mechanics during Embryonic Development. bioRxiv, 2021.

38. Schwartz, A.G., J.H. Lipner, J.D. Pasteris, G.M. Genin, and S. Thomopoulos, Muscle loading is necessary for the formation of a functional tendon enthesis. Bone, 2013. 55(1): p. 44-51.

39. Thomopoulos, S., H.-M. Kim, S.Y. Rothermich, C. Biederstadt, R. Das, and L.M. Galatz, Decreased muscle loading delays maturation of the tendon enthesis during postnatal development. Journal of Orthopaedic Research, 2007. 25(9): p. 1154-1163.

40. Subramanian, A., L.F. Kanzaki, J.L. Galloway, and T.F. Schilling, Mechanical force regulates tendon extracellular matrix organization and tenocyte morphogenesis through TGFbeta signaling. eLife, 2018. 7.

41. Paten, J.A., C.L. Martin, J.T. Wanis, S.M. Siadat, A.M. Figueroa-Navedo, J.W. Ruberti, and L.F. Deravi, Molecular Interactions between Collagen and Fibronectin: A Reciprocal Relationship that Regulates De Novo Fibrillogenesis. Chem, 2019. 5(8): p. 2126-2145.

42. Harris, A.K., D. Stopak, and P. Wild, Fibroblast traction as a mechanism for collagen morphogenesis. Nature, 1981. 290(5803): p. 249-51.

43. Guo, X., A.E. Hutcheon, S.A. Melotti, J.D. Zieske, V. Trinkaus-Randall, and J.W. Ruberti, Morphologic characterization of organized extracellular matrix deposition by ascorbic acid-stimulated human corneal fibroblasts. Investigative ophthalmology \& visual science, 2007. 48(9): p. 4050-4060.

44. Ren, R., A. Hutcheon, X. Guo, N. Saeidi, S. Melotti, J. Ruberti, J. Zieske, and V. TrinkausRandall, Human primary corneal fibroblasts synthesize and deposit proteoglycans in longterm 3-D cultures. Developmental Dynamics, 2008. 237(10): p. 2705-2715.

45. Siadat, S.M., A.A. Silverman, C.A. DiMarzio, and J.W. Ruberti, Measuring Collagen Fibril Diameter with Differential Interference Contrast Microscopy. Journal of Structural Biology, 2021: p. 107697.

46. Doane, K.J. and D.E. Birk, Fibroblasts retain their tissue phenotype when grown in threedimensional collagen gels. Exp Cell Res, 1991. 195(2): p. 432-42.

47. Bateman, J.F., W.G. Cole, J.J. Pillow, and J.A. Ramshaw, Induction of procollagen processing in fibroblast cultures by neutral polymers. J Biol Chem, 1986. 261(9): p. 4198203.

48. Kumar, P., et al., Macromolecularly crowded in vitro microenvironments accelerate the production of extracellular matrix-rich supramolecular assemblies. Sci Rep, 2015. 5: p. 8729.

49. Graham, J., M. Raghunath, and V. Vogel, Fibrillar fibronectin plays a key role as nucleator of collagen I polymerization during macromolecular crowding-enhanced matrix assembly. Biomater Sci, 2019. 7(11): p. 4519-4535.

50. Bhole, A.P., B.P. Flynn, M. Liles, N. Saeidi, C.A. Dimarzio, and J.W. Ruberti, Mechanical strain enhances survivability of collagen micronetworks in the presence of collagenase: implications for load-bearing matrix growth and stability. Philos Trans A Math Phys Eng Sci, 2009. 367(1902): p. 3339-62. 
51. Kress, H., E.H. Stelzer, D. Holzer, F. Buss, G. Griffiths, and A. Rohrbach, Filopodia act as phagocytic tentacles and pull with discrete steps and a load-dependent velocity. Proc Natl Acad Sci U S A, 2007. 104(28): p. 11633-8.

52. Birk, D.E. and R.L. Trelstad, Extracellular compartments in tendon morphogenesis: collagen fibril, bundle, and macroaggregate formation. J Cell Biol, 1986. 103(1): p. 23140.

53. ten Cate, A.R., Morphological studies of fibrocytes in connective tissue undergoing rapid remodelling. J Anat, 1972. 112(Pt 3): p. 401-14.

54. Cate, A.R. and D.A. Deporter, The degradative role of the fibroblast in the remodelling and turnover of collagen in soft connective tissue. Anat Rec, 1975. 182(1): p. 1-13.

55. Ten Cate, A.R. and D.A. Deporter, The role of the fibroblast in collagen turnover in the functioning periodontal ligament of the mouse. Arch Oral Biol, 1974. 19(4): p. 339-40.

56. Ten Cate, A.R. and E. Freeman, Collagen remodelling by fibroblasts in wound repair. Preliminary observations. Anat Rec, 1974. 179(4): p. 543-6.

57. Deporter, D.A. and A.R. ten Cate, Fine structural localization of acid and alkaline phosphatase in collagen-containing vesicles of fibroblasts. J Anat, 1973. 114(Pt 3): p. 45761.

58. Cate, A.R. and S. Syrbu, A relationship between alkaline phosphatase activity and the phagocytosis and degradation of collagen by the fibroblast. J Anat, 1974. 117(Pt 2): p. 351-9.

59. Siadat, S.M., On the mechanobiology of collagen growth and remodelling, in Department of Bioengineering2020, Northeastern University.

60. Everts, V., W. Beertsen, and W. Tigchelaar-Gutter, The digestion of phagocytosed collagen is inhibited by the proteinase inhibitors leupeptin and E-64. Coll Relat Res, 1985. 5(4): p. 315-36.

61. Everts, V. and W. Beertsen, The role of microtubules in the phagocytosis of collagen by fibroblasts. Coll Relat Res, 1987. 7(1): p. 1-15.

62. Beertsen, W., V. Everts, K. Hoeben, and A. Niehof, Microtubules in periodontal ligament cells in relation to tooth eruption and collagen degradation. J Periodontal Res, 1984. 19(5): p. 489-500.

63. Everts, V., R.M. Hembry, J.J. Reynolds, and W. Beertsen, Metalloproteinases are not involved in the phagocytosis of collagen fibrils by fibroblasts. Matrix, 1989. 9(4): p. 26676.

64. Rustom, A., R. Saffrich, I. Markovic, P. Walther, and H.H. Gerdes, Nanotubular highways for intercellular organelle transport. Science, 2004. 303(5660): p. 1007-10.

65. Kultti, A., K. Rilla, R. Tiihonen, A.P. Spicer, R.H. Tammi, and M.I. Tammi, Hyaluronan synthesis induces microvillus-like cell surface protrusions. J Biol Chem, 2006. 281(23): p. 15821-8.

66. Lin, W., S. Shuster, H.I. Maibach, and R. Stern, Patterns of hyaluronan staining are modified by fixation techniques. J Histochem Cytochem, 1997. 45(8): p. 1157-63.

67. Evanko, S.P., S. Potter-Perigo, P.Y. Johnson, and T.N. Wight, Organization of hyaluronan and versican in the extracellular matrix of human fibroblasts treated with the viral mimetic poly I:C. J Histochem Cytochem, 2009. 57(11): p. 1041-60.

68. Evanko, S.P., S. Potter-Perigo, L.J. Petty, G.A. Workman, and T.N. Wight, Hyaluronan Controls the Deposition of Fibronectin and Collagen and Modulates TGF-betal Induction of Lung Myofibroblasts. Matrix Biol, 2015. 42: p. 74-92. 
69. Guo, N., X. Li, M.M. Mann, M.L. Funderburgh, Y. Du, and J.L. Funderburgh, Hyaluronan Synthesis Mediates the Fibrotic Response of Keratocytes to Transforming Growth Factor $\beta$. Journal of Biological Chemistry, 2010. 285(42): p. 32012-32019.

70. Marchi, F. and C.P. Leblond, Collagen biogenesis and assembly into fibrils as shown by ultrastructural and 3 H-proline radioautographic studies on the fibroblasts of the rat food pad. Am J Anat, 1983. 168(2): p. 167-97.

71. Saunders, J.T. and J.E. Schwarzbauer, Fibronectin matrix as a scaffold for procollagen proteinase binding and collagen processing. Molecular Biology of the Cell, 2019. 30(17): p. 2218-2226.

72. Zhu, S.N., B. Nolle, and G. Duncker, Expression of adhesion molecule CD44 on human corneas. British Journal of Ophthalmology, 1997. 81(1): p. 80-84.

73. Al-Rekabi, Z., A.M. Fura, I. Juhlin, A. Yassin, T.E. Popowics, and N.J. Sniadecki, Hyaluronan-CD44 interactions mediate contractility and migration in periodontal ligament cells. Cell Adhesion \& Migration, 2019. 13(1): p. 139-151.

74. Masur, S.K., J.K. Cheung, and S. Antohi, Identification of integrins in cultured corneal fibroblasts and in isolated keratocytes. Invest Ophthalmol Vis Sci, 1993. 34(9): p. 2690-8.

75. Stepp, M.A., Corneal integrins and their functions. Exp Eye Res, 2006. 83(1): p. 3-15.

76. Bueno, E.M., N. Saeidi, S. Melotti, and J.W. Ruberti, Effect of serum and insulin modulation on the organization and morphology of matrix synthesized by bovine corneal stromal cells. Tissue Eng Part A, 2009. 15(11): p. 3559-73.

77. Church, R.L., Procollagen and collagen produced by normal bovine corneal stroma fibroblasts in cell culture. Invest Ophthalmol Vis Sci, 1980. 19(2): p. 192-202.

78. Baneyx, G. and V. Vogel, Self-assembly of fibronectin into fibrillar networks underneath dipalmitoyl phosphatidylcholine monolayers: Role of lipid matrix and tensile forces. Proceedings of the National Academy of Sciences, 1999. 96(22): p. 12518-12523.

79. Hayes, A., M. Isaacs, C. Hughes, B. Caterson, and Ralphs, Jr., Collagen fibrillogenesis in the development of the annulus fibrosus of the intervertebral disc. European Cells and Materials, 2011. 22: p. 226-241.

80. Coulombre, A.J., The Role of Intraocular Pressure in the Development of the Chick Eye. A.M.A. Archives of Ophthalmology, 1957. 57(2): p. 250.

81. Ambrosi, D., M. Ben Amar, C.J. Cyron, A. Desimone, A. Goriely, J.D. Humphrey, and E. Kuhl, Growth and remodelling of living tissues: perspectives, challenges and opportunities. Journal of The Royal Society Interface, 2019. 16(157): p. 20190233.

82. Bell, E., B. Ivarsson, and C. Merrill, Production of a tissue-like structure by contraction of collagen lattices by human fibroblasts of different proliferative potential in vitro. Proc Natl Acad Sci U S A, 1979. 76(3): p. 1274-8.

83. Murtha, L.A., M.J. Schuliga, N.S. Mabotuwana, S.A. Hardy, D.W. Waters, J.K. Burgess, D.A. Knight, and A.J. Boyle, The Processes and Mechanisms of Cardiac and Pulmonary Fibrosis. Front Physiol, 2017. 8: p. 777.

84. Layton, T.B., et al., Cellular census of human fibrosis defines functionally distinct stromal cell types and states. Nature Communications, 2020. 11(1).

85. Siadat, S.M., M.E. Susilo, J.A. Paten, A.A. Silverman, C.A. DiMarzio, and J.W. Ruberti, Development and Validation of Fluorescently Labeled, Functional Type I Collagen Molecules. bioRxiv, 2021: p. 2021.03.26.437209. 